tional co-ordination. To place the Department of Veterinary Clinical Studies in the Faculty of Medicine of the University of Cambridge is thus a step towards the comparative approach to medicine. The clinician has already learned to go to the pathologist and biochemist for aid, and it is regrettable that he has not turned more often to the physiologist. The latter works particularly with the dog and the cat-two animals with which the veterinarian is concerned-and it is time that many of the findings with laboratory animals should be extended to the farm animals.

Prof. Pugh concludes as follows: "Basically there are two problems. Is there a place in the intellectual structure of this University for a clinical department, and is there a place for a veterinary school ? I hope that the opinion advanced may at least 'provoke those it cannot convert'.

"I have tried to express the aim that veterinary medicine must develop its own science of experimental medicine; I have suggested an approach to this problem in the hope that not only will it enlarge our understanding of disease, but will make for a closer relationship with the other scientific disciplines and create a logical sequence of ideas in teaching. In pursuing this object, the veterinarian's interest in different animals suggests that it is ultimately by a comparative approach that a clinical department can best play its part in the furtherance of knowledge and that, by this approach, the fundamental similarities and dissimilarities between species, in which I include man, may be profitably exploited".

\title{
CAVITATION IN HYDRODYNAMICS
}

$\mathrm{C}$ AVITATION is a subject of growing scientific and technical interest, and the first international symposium to be devoted entirely to it was organized by, and held at, the National Physical Laboratory, Teddington, during September 14-16. The word itself was coined sixty years ago by R. E. Froude to describe the process which he visualized as responsible for the unexpectedly poor performance of high-speed propellers fitted to a naval vessel just then completed; his imaginative speculation that the very low pressures existing in some regions of the flow through the propeller caused the formation of cavities in the water was soon shown to be correct by Parsons, and since then naval architects have frequently been concerned to detect and overcome the harmful effects of this breakdown in homogeneous flow. The same problems were later found to occur in hydraulic machines, and more recently cavitation phenomena have become important in such different fields as ultrasonics and underwater projectiles and explosions. This has naturally led to more detailed study of the basic mechanism of cavitation, and during the past few years much has been learned about the behaviour of individual cavities and the factors which control their inception, while considerable progress has also been made in understanding the nature of erosion damage due to cavitation.

It was because of this recent increase in research on cavitation problems that it was considered appropriate to hold a symposium at Teddington to discuss the progress made; because of the special interests of the Ship Division of the National Physical Laboratory, the problems of cavitation in hydrodynamics were selected for special examination, and the programme of the meetings was designed to proceed from discussion of the fundamental physics of the phenomena to consideration of the hydrodynamic effects of cavitation on performance and damage, and to methods recently developed for their study. The symposium was divided into six half-day sessions, at the first of which an opening address of a general nature was presented, while the other five sessions, at which a total of twenty papers was given, were each devoted to a different aspect of hydrodynamic cavitation. In addition to these formal meetings, a further informal session was arranged during the symposium to meet the wishes of those particularly interested in ultrasonic cavitation for a discussion of their problems. A total of about a hundred and thirty delegates from fourteen countries attended the meetings, of whom more than half took an active part as authors of papers or as contributors to the discussions. Special care was taken to give adequate time during the sessions for discussion by firmly limiting each author to fifteen minutes when presenting his paper, and several of the ensuing discussions were extremely lively and instructive. The symposium proceedings, including summaries of these discussions, will be published by H.M. Stationery Office in about six months.

The opening address, given by Mr. P. Eisenberg (United States Office of Naval Research), was a critical review of recent progress in cavitation research, and discussed the origin and stability of entrained gas nuclei and their effects on inception, the influences of turbulence and boundary-layer flow conditions, the present knowledge of the dymamics of transient and steady-state cavities, and the status of research on theories of cavitation damage. $\mathrm{He}$ concluded that during the past few years there have been two main accomplishments : the basic problems have been more sharply defined, and the physical phenomena that must be considered in their investigation have been more clearly identified. Mr. Eisenberg emphasized that the questions awaiting answer for immediate engineering application are the very ones which require an understanding of some of the most complex and least understood phenomena in hydromechanics. The chairman, Dr. J. F. Allan (superintendent of the Ship Division of the National Physical Laboratory), commended this conclusion, and forecast that developments in ship propulsion would bring cavitation into more prominence and accentuate the need for practical solutions to its difficulties.

The second session, with Dr. R. W. L. Gawn (superintendent of the Admiralty Experiment Works) as chairman, was concerned with the factors governing inception of cavitation. The effects of dissolved and entrained gas content, the ability of water to sustain considerable tensions under dynamic conditions, and the growth of gas nuclei, particularly those in boundary-layer flows, were the main topics of discussion. It was clear that a means of determining the spectrum of entrained bubble size in flowing water was much needed, and that acoustic methods, often used as criteria of cavitation inception, offer possibilities in this direction. This discussion led naturally to the consideration of experiment techniques, the subject of the next session, at which Prof. 
W. P. A. van Lammeren (Netherlands Ship Model Basin) was in the chair. Instruments for measuring fluctuating forces, pressures and velocities and others specially developed for new Admiralty large-scale test facilities were described, while one paper gave details of high-speed photographic methods (with pictures taken at rates of up to 1 million per second) designed for studies of individual bubbles in ultrasonic cavitation, which have a life-cycle, during which intense collapse pressures are generated, encompassed in $l \mu$ sec. A paper outlining the performance characteristics of a small experimental water tunnel led to a vigorous discussion of the virtues of re-absorption devices (inelegantly but widely known as resorbers) in large-scale cavitation testing rigs. Many new water tunnels, including a large new propeller tunnel to be built for the National Physical Laboratory, incorporate expensive resorbers, and the general consensus of opinion seemed to be that these are desirable provided sufficient money is available.

Even large test facilities for ship propellers and water turbines can only handle models which are small compared with their prototypes, and thus scaleeffect factors are of great importance in cavitation studies. The papers at the fourth session of the symposium, under Prof. J. W. Daily (Massachusetts Institute of Technology), dealt with this thorny problem, and the relative importance of the significant parameters, particularly the Froude, Reynolds and Weber numbers, was discussed. One paper gave some disturbing preliminary results from a series of geometrically similar model propellers, and another showed remarkable Admiralty photographs of propeller cavitation patterns taken during ship trials of a destroyer and other naval vessels. The following session, with Mr. F. S. Burt (Admiralty Research Laboratory) as chairman, was concerned with a related problem - the effects of cavitation on the hydrodynamic performance of foils. Valuable data on the properties of hydrofoils under super- cavitating conditions (when fully developed, steadystate cavities spring from the leading edge) were given in a group of papers and supplemented in the discussion. A pleasant, and valuable, interlude here was an excellently produced film, with full colour and sound, showing some of the pioneering work being done at the California Institute of Technology. Finally, the delegates turned their attention to the vexed question of cavitation damage, and the papers delivered at this session presented very different views on the mechanism of damage erosion, the upholders of the two schools of impingement attack and corrosion fatigue being in evidence. The qualities of cathodic protection as a damage inhibitor, and the role of gas in water as a damage 'cushion', were also argued. The damage potential of cavities of fixed type, shown to have a fiercely periodic nature with violent downstream collapse conditions, was also brought out; and if this session cannot claim to have resolved the opposed views, it certainly did much to clarify them. Mr. Eisenberg, chairman at this session, persuaded Prof. J. Ackeret (Zurich), a pioneer in this field, to remind the delegates of some highly pertinent effects of shock waves in causing damage, and in his own closing remarks commented that the programme of the symposium had clearly brought out the central problems for discussion. Dr. Allan, responding for the National Physical Laboratory, regretted that the delegates had had to remain almost silent on the problems of cavitation noise; but hoped that in spite of this the meetings would encourage further research which would extend our knowledge and control of cavitation phenomena. Dr. Allan felt that this research should not be organized on an internationally agreed programme, perhaps not even on a national basis, but that individual workers should pursue their own interests and meet at intervals to exchange views. This suggests that the first conference on cavitation problems will be followed by others.

A. Silverleaf

\section{DEATH AND THE AFTER-LIFE}

$\mathrm{T}$ HE general theme, "Disposal of the Dead, and Beliefs in an After-Life", was selected as the main part of the programme of Section $H$ (Anthropology and Archæology) at the recent Bristol meeting of the British Association, because experience had shown the need for a common topic about which anthropologists and archæologists desired each to hear what the others had to say, and the theme chosen provided scope for participation by nearly all elements in the section. With one or two exceptions, the papers were grouped in the sessions as indicated by the headings.

\section{From the Origin of Man to the Mesolithic Period}

The evidence from pre-Neolithic peoples was discussed in the opening session by Dr. Kenneth Oakley, Mr. Miles Burkitt and Dr. L. H. Wells. In his paper on "Earliest Evidence of Disposal of the Dead", Dr. Oakley remarked on the tendency, among gregarious non-human primates, for the dying animal to leave the sleeping-place of the troop. He then dealt with cannibalism, which was widespread before disposal of the dead by ceremonial or careful burial became regular. All the remains of Pekin man in the Choukoutien cave deposits are judged to be the debris of cannibal feasts. The bones of Neanderthalers in the Krapina cave appear to have been deliberately broken, and many were charred; the female skull from Ehringsdorf shows evidence of mortal blows; the breaking of the Steinheim skull was evidently deliberate, and all the eleven Solo (Ngandong, Java) skulls have their bases and facial bones missing as if broken for extraction of their brains. The base of the Neanderthal skull found within a ring of stones on the floor of the Goat's Cave in Monte Circeo has clearly had the foramen magnum enlarged for this purpose. Therefore, it appears that head-hunting and brain-eating were characteristic of these early periods.

Mr. Miles Burkitt then dealt with "Middle and Upper Palæolithic Burials". It was not only the 'old man' of the family, but also women and children who were carefully buried. At La Chapelle aux Saints, it is true, there was only one burial of a man in a sepulchral cave, with evidence that the interment had taken place with care and ceremony ; but at La Ferrassie the whole family were buried in what presumably had been their home, with care and possibly some sort of ritual, as the body of one of the children was covered by an artificially cupmarked stone. Other Mousterian burials are known. Whether the reason for this care for some of the 